\title{
Studi Analisis Stabilitas Dinding Penahan Tanah Semi Gravitasi Pada Ruas Jalan Sorong-Aimas Km 18 Kota Sorong
}

\author{
Arief Indriyanto ${ }^{1}$, Rokhman $^{2}$ \\ ${ }^{1}$ Mahasiswa Program Studi Teknik Sipil Universitas Muhammadiyah Sorong \\ ${ }^{2}$ Dosen Program Studi Teknik Sipil Universitas Muhammadiyah Sorong
}

\begin{abstract}
Abstrak
Infrastruktur sebagai sarana transportasi merupakan hal yang sangat penting untuk diperhatikan, khususnya yang menggunakan angkutan darat. Apabila diperhatikan, ada ratusan angkutan darat yang melintas setiap harinya dan hal ini, tidak dapat dilepaskan dari peran insfrastruktur jalan sebagai salah satu bagi angkutan darat tersebut melakukan aktifitasnya. Perlindungan infrastruktur dari bahaya longsoran merupakan hal penting agar prasarana tersebut dapat digunakan,Salah satu cara untuk mencegah terjadinya kelongsoran adalah dengan membangun dinding penahan tanah. Studi ini bertujuan untuk menganalisis stabilitas dinding penahan tanah semi gravitasi pada ruas jalan km 18 SorongAimas terhadap gaya guling, geser, dan daya dukung tanahnya. Perhitungan tekanan tanah dihitung dengan menggunakan Teori Coulomb serta perhitungan stabilitas terhadap keruntuhan kapasitas daya dukung tanah dihitung berdasarkan persamaan Vesic. Data-data yang diperlukan untuk analisa perhitungan di dapat dari hasil pengujian tanah di laboratorium Mekanika Tanah Jurusan Teknik Sipil Universitas Muhammadiyah Sorong. Hasil perhitungan stabilitas dinding penahan tanah terhadap penggulingan $(\mathrm{fgl})=2,912$, terhadap penggeseran $(\mathrm{fgs})=2,598$, dan terhadap daya dukung tanah $(\mathrm{fdt})=3,011$.
\end{abstract}

Kata kunci : stabilitas, dinding penahan tanah, semi gravitasi, uji geser langsung

\section{Pendahuluan}

Infrastruktur sebagai sarana transportasi merupakan hal yang sangat penting untuk diperhatikan, khususnya yang menggunakan angkutan darat. Apabila diperhatikan, ada ratusan angkutan darat yang melintas setiap harinya dan hal ini, tidak dapat dilepaskan dari peran insfrastruktur jalan sebagai salah satu bagi angkutan darat tersebut melakukan aktifitasnya. Perlindungan infrastruktur dari bahaya longsoran merupakan hal penting agar prasarana tersebut dapat digunakan.

Di daerah jalan Sorong-Aimas cenderung berbukit dan di tambah curah hujan yang cenderung tinggi maka ada bagian pada sisi jalan yang mengalami kelongsoran. Salah satu cara untuk mencegah terjadinya kelongsoran adalah dengan membangun dinding penahan tanah. Salah satu contoh yang dapat kita lihat adalah pada jalan Sorong-Aimas Km 18, untuk mencegah kelongsoran pada ruas jalan sudah dibangun dinding penahan tanah bertipe Dinding Semi Gravitasi atau pemasangan batu bertulang.

\section{Metode}

\section{Tahapan Penelitian}

Pada penelitian ini penulis menggunakan metode seperti berikut :

1. Mengumpulkan data-data dinding penahan tanah yang ada di lokasi penelitian meliputi data primer (foto dokumentasi, pengukuran lereng dengan menggunakan theodolit, mengambil sampel tanah untuk mengetahui sifat fisik tanah) dan data skunder (data sondir, gambar kerja dan hasil kajian literature tentang dinding penahan tanah).

2. Melakukan pengujian sampel di laboratorium.

3. Mengolah data pengukuran maupun data hasil uji laboratorium.

4. Menganalisis stabilitas stabilitas dinding penahan tanah terhadap bahaya guling, geser, dan daya dukung tanahnya dengan menggunakan metode Hansen dan Vesic .

\section{Peralatan Yang digunakan}

Beberapa peralatan yang dipakai untuk menunjang penelitian ini sebagai berikut:

1. Theodolit untuk pengukuran lereng. 
2. Hand Boring untuk membantu mengambil sampel tanah.

3. Oven untuk mengeringkan sampel di laboratorium.

4. Piknometer untuk pegujian berat jenis.

5. Hydrometer untuk pengujian analisa ukuran butir.

6. Direct Shear Test untuk pengujian kuat geser tanah.

\section{Hasil dan Pembahasan Sifat fisik tanah}

Tanah dari lokasi penelitian yang diambil menggunakan alat Bor manual yang berada didalam pipa besi kemudian dibawa ke laboratorium untuk di uji. Berikut hasil rekapituasi pengujian di laboratorium:

Tabel 1. Hasil Pengujian Sifat Fisik dan Mekanik Sampel Tanah

\begin{tabular}{|c|c|c|c|c|}
\hline \multirow[b]{2}{*}{ No } & \multirow[b]{2}{*}{$\begin{array}{c}\text { Jenis } \\
\text { Pengujian }\end{array}$} & \multicolumn{3}{|c|}{ Sampel } \\
\hline & & $\begin{array}{l}\text { Atas (I) } \\
0-1 \mathrm{~m}\end{array}$ & $\begin{array}{l}\text { Tengah } \\
\text { (II) } \\
0-1 \mathrm{~m}\end{array}$ & $\begin{array}{c}\text { Bawah(III) } \\
0-1 \mathrm{~m}\end{array}$ \\
\hline 1 & $\begin{array}{c}\text { Kadar Air } \\
(\%)\end{array}$ & 36,24 & 34,15 & 38,34 \\
\hline 2 & $\begin{array}{l}\text { Berat isi } \\
\left(\mathrm{gr} / \mathrm{cm}^{3}\right)\end{array}$ & 1,80 & 1,95 & 1,94 \\
\hline 3 & $\begin{array}{c}\text { Berat Jenis } \\
\text { Lolos }\end{array}$ & 2,54 & 2,58 & 2,64 \\
\hline 4 & $\begin{array}{c}\text { Saringan No. } \\
200(\%)\end{array}$ & 72,80 & - & - \\
\hline 5 & $\begin{array}{c}\text { Atterberg } \\
\text { Limit }\end{array}$ & - & - & - \\
\hline & LL (\%) & 61 & - & - \\
\hline & PL (\%) & 31 & - & - \\
\hline & PI (\%) & 30 & - & - \\
\hline 6 & $\begin{array}{c}\text { Direct Shear } \\
\text { Test }\end{array}$ & - & - & - \\
\hline & $\begin{array}{r}\text { Kohesi } \\
\left(\mathrm{kg} / \mathrm{cm}^{2}\right)\end{array}$ & 0,042 & 0,07 & 0,058 \\
\hline & Sudut Gesek & 24 & 24 & 28 \\
\hline
\end{tabular}

\section{Klasifikasi Tanah}

Dari hasil pengujian tanah di laboratorium didapat sifat fisik tanah yang nanti akan membantu dalam proses pengelompokan tanah berdasarkan spesifikasinya. Hail pengelompokan klasifikasi tanah menurut system AASHTO yaitu analisa saringan lolos nomer $40(0,425) \quad 83,45>51 \%$, dengan indeks plastisitas $(\mathrm{PI})=30$ maka dapat diklasifikasikan sebagai kelompok A-7-5 yaitu tipe material yang dominan adalah tanah berlempung sedang sampai buruk.

\section{Stabilitas Dinding Penahan Tanah}

Dari hasil analisis dan perhitungan terhadap kestabilitas dinding penahan tanah pada ruas jalan Sorong-Aimas km 18, maka dapat disimpulkan halhal sebagai berikut:

Tabel 2. Hasil Perhitungan Stabilitas Dinding Penahan Tanah. (Bowles, 1989)

\begin{tabular}{|c|c|c|c|}
\hline Stabilitas & $\begin{array}{c}\text { Hasil } \\
\text { Perhitungan }\end{array}$ & $\begin{array}{l}\text { Faktor } \\
\text { Aman }\end{array}$ & Kesimpulan \\
\hline Penggulingan & 2,912 & $>1.5$ & Aman \\
\hline Penggeseran & 2,598 & $>1.5$ & Aman \\
\hline $\begin{array}{l}\text { Daya dukung } \\
\text { tanah }\end{array}$ & 3,011 & $>3$ & Aman \\
\hline
\end{tabular}

\section{Analisa Dinding Penahan Tanah}

Analisa dimding penahan tanah ditinjau salah satu titik yaitu titik $0+120$, untuk mewakili perhitungan diambil per 1 meter

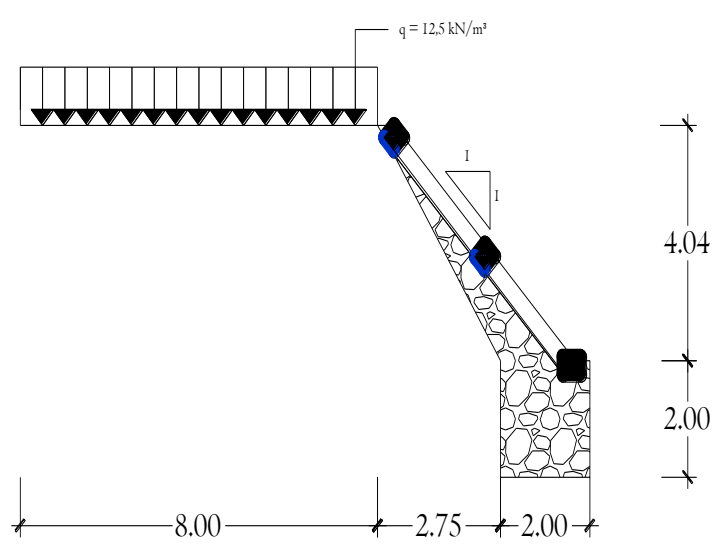

Gambar 1. Dinding Penahan Tanah di Titik $0+120 \mathrm{~m}$

\section{Berat Sendiri Dinding Penahan Tanah}

Berat dinding penahan tanah dihitung berdasarkan bahan yang di pakai, berat dinding penahan tanah pada ruas jalan $\mathrm{km} 18$ menggunakan ketetepan berat jenis pasangan batu yaitu $22 \mathrm{kN} / \mathrm{m}^{3}$ dan beton sebesar $24 \mathrm{kN} / \mathrm{m}^{3}$, sedangkan berat dinding penahan itu sendiri adalah perkalian antara luas bangunan dan volume batu atau beton. 
Tabel 3. Berat Dinding Penahan Tanah

\begin{tabular}{cccccc}
\hline & & Jarak x & Jarak y & Momen x ke & Momen y ke \\
& & Beratw $(\mathrm{kN})$ & $(\mathrm{m})$ & $\mathrm{O}\left(\mathrm{kN} / \mathrm{m}^{3}\right)$ & $\mathrm{O}\left(\mathrm{kN} / \mathrm{m}^{3}\right)$ \\
\hline 1 & $5,9424 \times 22=130,7328$ & 1,5034 & 1,7425 & 196,5437 & 227,8019 \\
& & & & & \\
2 & $2,1598 \times 24=51,8352$ & 2,4426 & 3,8621 & 126,6127 & 200,1927 \\
& & & & & \\
\hline & 182,5680 & & & 323,1564 & 427,9946
\end{tabular}

\section{Perhitungan Tekanan Tanah}

Koefisien tekanan tanah pasif $(\mathrm{Kp})$ dengan metode Coulomb

$$
\begin{aligned}
\mathrm{Kp} & =\frac{\sin ^{2}(\alpha-\phi)}{\sin ^{2} \alpha \sin (\alpha+\delta)\left[1-\sqrt{\frac{\sin (\phi+\delta) \sin (\phi+\beta)}{\sin (\alpha+\delta) \sin (\alpha+\beta)}}\right]^{2}} \\
\mathrm{Kp} & \left.=\frac{\sin ^{2}(90-24)}{\sin ^{2} 90 \sin (90+16)\left[1-\sqrt{\frac{\sin (24+16) \sin (24+0)}{\sin (90+16) \sin (90+0)}}\right.}\right] \\
& =\frac{0,834}{0,219} \\
& =3,808
\end{aligned}
$$

Tekanan Tanah Pasif (Pp)

$$
\begin{aligned}
\mathrm{Pp} & =0,5 \mathrm{H}^{2} \gamma \mathrm{Kp}+2 \mathrm{c} \sqrt{\mathrm{Kp}} \\
& =0,51^{2} 18,43,808+25,493 \sqrt{3}, 808 \\
& =35,033+21,433 \\
& =56,466 \mathrm{kN}
\end{aligned}
$$

Koefisien tekanan tanah aktif (ka) dengan metode Coulomb

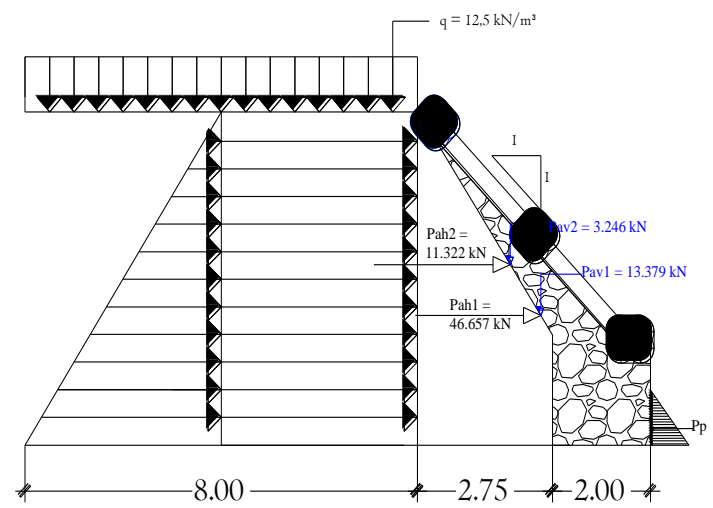

$$
\begin{aligned}
\mathrm{Ka} & =\frac{\sin ^{2}(\alpha+\varphi)}{\sin ^{2} \alpha \sin (\alpha-\delta)\left[1+\sqrt{\frac{\sin (\varphi+\delta) \sin (\varphi-\beta)}{\sin (\alpha-\delta) \sin (\alpha-\beta)}}\right]^{2}} \\
& =\frac{0,235}{1,509} \\
& =0,156
\end{aligned}
$$

Tekanan Tanah Aktif (Pa)

$$
\mathrm{Pa}=0,5 \mathrm{H}^{2} \gamma \mathrm{Ka}-2 \mathrm{c} \sqrt{\mathrm{Ka}}+\mathrm{qH} \mathrm{Ka}
$$

$$
\begin{aligned}
\mathrm{Pah} & =\mathrm{Pa} \cos (\delta) \\
\mathrm{Pav} & =\mathrm{Pa} \sin (\delta) \\
\delta & =\frac{2}{3} \varphi \\
& =\frac{2}{3} 24 \\
& =16^{\circ}
\end{aligned}
$$

Tabel 4. Tekanan tanah aktif pada dinding penahan tanah

\begin{tabular}{ccccccc}
\hline No & $\mathrm{Pa}(\mathrm{kN})$ & & $\mathrm{Pah}(\mathrm{kN})$ & $\mathrm{Pav}(\mathrm{kN})$ & $\mathrm{x}(\mathrm{m})$ & $\mathrm{y}(\mathrm{m})$ \\
\hline 1 & $\left(0,5 \times 6,04^{2} \times 18,6 \mathrm{x} 0,156\right)-$ & & & & & \\
& $(2 \times 5,558 \times \sqrt{ } \sqrt{0} 156)=$ & 48,537 & 46,657 & 13,379 & 2,917 & 2,013 \\
2 & $12,5 \times 6,04 \times 0,156=$ & 11,778 & 11,322 & 3,246 & 3,375 & 3,020 \\
$\Sigma$ & & 60,315 & 57,979 & 16,625 & & \\
& & & & & &
\end{tabular}

Gambar 2. Tekanan tanah pada dinding penahan tanah

\section{Tinjauan Keamanan Terhadap Dinding}

Dinding penahan tanah dapat dikatakan aman apabila telah di hitung faktor amannya, baik terhadap bahaya pergeseran bahaya penggulingan, dan kemampuan daya dukung tanah.

Stabilitas Terhadap Penggulingan

Bangunan dinding penahan tanah dikatakan aman apabila angka keamanan lebih dari 1,5, dan dikatakan guling apabila angka keaman kurang dari 1,5 (faktor aman yang disyaratkan). (Bowles, 1989)

$$
\begin{aligned}
\mathrm{Fgl} & =\frac{\sum \mathrm{Mx}+\Sigma \text { Pav } \mathrm{x}}{\Sigma \text { pah } \mathrm{y}} \\
& =\frac{323,1564+((13,379 \times 2,917)+(3,246 \times 3,375))}{(46,657 \times 2,013)+(11,322 \times 3,020)} \\
& =\frac{373,134}{128,127} \\
& =2,912>1,5 \text { (Dinding penahan tanah aman } \\
& \text { terhadap bahaya guling). }
\end{aligned}
$$

\section{Stabilitas Terhadap Geser}

Bangunan dinding penahan tanah dikatakan aman apabila angka keamanan lebih dari 1,5, dan dikatakan guling apabila angka keaman kurang dari 1,5 (faktor aman yang disyaratkan). (Bowles,1989)

$\mathrm{Fgs}=\frac{(\Sigma \mathrm{W}+\Sigma \mathrm{Pav}+(\mathrm{cxB}) \operatorname{tg} \varphi)+\mathrm{Pp}}{\Sigma \mathrm{Pah}}$

$$
=\frac{((182,5680+(13,3786+3,2465)+(5,558 \times 2) \operatorname{tg} 25,3)+56,466}{57,979}
$$


$=\frac{150,624}{57,979}$

$=2,598>1,5$ (Dinding penahan tanah aman terhadap bahaya penggeseran).

Stabilitas Terhadap Keruntuhan Daya Dukung Tanah

Kapasitas dukung tanah ultimit dihitung menggunakan persamaan Hansen untuk beban miring dan eksentris sehinggah dapat dirumuskan :

$$
\begin{aligned}
\chi & =\frac{\Sigma \mathrm{Mx}-\Sigma \mathrm{Pah} \mathrm{y}}{\Sigma \mathrm{W}+\Sigma \mathrm{Pav}} \\
& =\frac{373,134-128,127}{182,5680+(13,3786+3,2465)} \\
& =\frac{245,007}{199,193} \\
& =1,230 \text { m dari titik } \mathrm{O}
\end{aligned}
$$

Eksentrisitas $\mathrm{e}=(\mathrm{B} / 2)-\chi=(2 / 2)-1,230=$ $0,230<\mathrm{B} / 6=0,333$

Tekanan pada dasar dinding menggunakan persamaan Terzaghi 1943

$$
\begin{aligned}
\mathrm{q} & =\frac{\mathrm{V}}{\mathrm{B}}\left(1+\frac{6 \mathrm{e}}{\mathrm{B}}\right) \\
& =\frac{199,193}{2}\left(1+\frac{6 \times 0,230}{2}\right) \\
& =\frac{199,193}{2}\left(1+\frac{1,38}{2}\right) \\
& =99,5965(1,19) \\
& =118,520 \mathrm{kN} / \mathrm{m}^{2}<\mathrm{q}_{\mathrm{c}}=25133,22 \mathrm{kN} / \mathrm{m}^{2}
\end{aligned}
$$

Lebar efektif dengan metode rumus Meyerhof :

$$
\begin{aligned}
\mathrm{B}^{\prime} & =\mathrm{B}-2 \mathrm{e} \\
& =2-(2 \times(0,230)) \\
& =1,54 \mathrm{~m}
\end{aligned}
$$

Dari perhitungan didapat gaya horizontal $\mathrm{H}=$ $57,979 \mathrm{kN}$ dan gaya vertikal $\mathrm{V}=199,193 \mathrm{kN}$. Untuk $\varphi=28^{\circ}$, dari tabel faktor-faktor daya dukung Hansen (1961) diperoleh $\mathrm{Nc}=25,80, \mathrm{Nq}=14,72$, $\mathrm{N} \gamma=10,94$.

Faktor kemiringan beban (Hansen,1970) :

$$
\begin{aligned}
\mathrm{i}_{\mathrm{q}} & =\left(1-\frac{0,5 \mathrm{H}}{\mathrm{V}+\mathrm{A}^{\prime} \mathrm{c} \operatorname{ctg} \varphi}\right)^{5} \geq 0 \\
& =\left(1-\frac{0,557,979}{199,193+1,545,689 \mathrm{ctg} 28^{\circ}}\right)^{5} \\
& =\left(1-\frac{28,989}{199,193+8,752}\right)^{5}
\end{aligned}
$$

$$
\begin{aligned}
& =\left(1-\frac{28,989}{207,945}\right)^{5} \\
& =(0,861)^{5} \\
& =0,472 \\
\mathrm{i}_{\mathrm{c}} & =\mathrm{i}_{\mathrm{q}}-\frac{1-\mathrm{iq}}{\mathrm{Nq}-1} \\
& =0,472-\frac{1-0,472}{14,72-1} \\
& =0,472-\frac{0,528}{13,72} \\
& =0,434 \\
\mathrm{I} \gamma & =\left(1-\frac{0,7 \mathrm{H}}{\mathrm{V}+\mathrm{B}^{\prime} \mathrm{c} \mathrm{ctg}}\right)^{5} \\
& =\left(1-\frac{0,757,979}{199,193+1,545,689 \mathrm{ctg} 28^{\circ}}\right)^{5} \\
& =\left(1-\frac{40,5853}{199,193+8,752}\right)^{5} \\
& =\left(1-\frac{40,5853}{207,945}\right)^{5} \\
& =(0,805)^{5} \\
& =0,338
\end{aligned}
$$

Faktor kedalaman pondasi ( Hansen, 1970 ) :

$$
\begin{aligned}
\mathrm{d}_{\mathrm{c}} & =1+0,4 \frac{\mathrm{Df}}{\mathrm{B}} \\
& =1+0.4 \frac{1}{2} \\
& =1,2 \\
\mathrm{~d}_{\mathrm{q}} & =1+2\left(\frac{\mathrm{Df}}{\mathrm{B}}\right) \operatorname{tg} \varphi(1-\sin \varphi)^{2} \\
& =1+2\left(\frac{1}{2}\right) \operatorname{tg} 28(1-\sin 28)^{2} \\
& =1+0,532(0,288) \\
& =1+0,163 \\
& =1,163 \\
\mathrm{~d} \gamma & =1
\end{aligned}
$$

Kapasitas dukung ultimit untuk pondasi dipermukaan dihitung menggunakan persamaan Hansen dan Vesic (1975) :

$$
\begin{aligned}
\mathrm{q}_{\mathrm{u}}= & \mathrm{d}_{\mathrm{C}} \mathrm{i}_{\mathrm{c}} \mathrm{c} \mathrm{N}_{\mathrm{c}}+\mathrm{d}_{\mathrm{q}} \mathrm{i}_{\mathrm{q}} \mathrm{Df} \gamma \mathrm{N}_{\mathrm{q}}+\mathrm{d} \gamma \mathrm{i} \gamma 0,5 \mathrm{~B} \gamma \mathrm{N} \gamma \\
= & (1,2 \times 0,434 \times 5,689 \times 25,80)+(1,163 \times 0,472 \times 1 \times 19 \times \\
& 14,72)+(1 \times 0,338 \times 0,5 \times 2 \times 19 \times 10,94) \\
= & 76,365+153,542+69,935 \\
= & 299,842 \mathrm{kN} / \mathrm{m}^{2}
\end{aligned}
$$

Bila dihitung dengan berdasarkan lebar pondasi efektik, yaitu tekanan pondasi ketanah terbagi merata, maka :

$$
\begin{aligned}
\mathrm{q}^{\prime} & =\frac{\mathrm{V}}{\mathrm{B}} \\
& =\frac{199,193}{2} \\
& =99,597 \mathrm{kN} / \mathrm{m}^{2}
\end{aligned}
$$


dukung:

Faktor aman terhadap keruntuhan kapasitas

$$
\begin{aligned}
\mathrm{F} & =\frac{\mathrm{qu}}{\mathrm{q}^{\prime}} \\
& =\frac{299,842}{99,597} \\
& =3,011>3 \text { (dinding penahan tanah aman } \\
& \text { terhadap keruntuhan kapasitas dukung tanah). } \\
& \text { (Bowles, 1989) }
\end{aligned}
$$

\section{Kesimpulan}

Dari hasil analisis dan perhitungan terhadap kestabilitas dinding penahan tanah pada ruas jalan Sorong-Aimas km 18, maka dapat disimpulkan halhal sebagai berikut:

- Berdasarkan hasil analisis faktor aman terhadap penggulingan (Fgl) didapat hasil sebagai berikut $: \mathrm{Fgl}=2,912>1,5$ (faktor aman), dengan hasil analisis penggulingan lebih besar dari faktor aman bisa dikatakan struktur aman terhadap bahaya penggulingan.

- Berdasarkan hasil analisis faktor aman terhadap penggeseran (Fgs) didapat hasil sebagai berikut : Fgs $=2,598>1,5$ (faktor aman), dengan hasil analisis penggeseran lebih besar dari faktor aman bisa dikatakan struktur aman terhadap bahaya penggeseran.

- Berdasarkan hasil analisis faktor aman terhadap daya dukung tanah (Fdt) didapat hasil sebagai berikut : Fdt = 3,011 > 3 (faktor aman), dengan hasil analisis daya dukung tanah lebih besar dari faktor aman bisa dikatakan struktur aman terhadap keruntuhan daya dukung tanah.

\section{Referensi}

Braja M. Das (1995), Mekanika Tanah 1, Surabaya : Penerbit Erlangga.

E. Sutarman (2013), Konsep dan Aplikasi Mekanika Tanah, Yogyakarta : Penerbit Andi.

G. Djatmiko Soedarmo, S. J. Edy Purnomo (1997), Mekanika Tanah 1, Yogyakarta: Penerbit Kanisius.

Hary Cristady Hardiyatmo (2002), Teknik Pondasi 1 Edisi ke-2, Yogyakarta: Beta Offset. 